Case Report

\title{
Refractory Classical Hodgkin Lymphoma Presenting with Atypical Cutaneous Involvement and Diagnosis of ZZ Phenotype Alpha-1 Antitrypsin Deficiency
}

\author{
Mohamad Khawandanah, ${ }^{1}$ Teresa Kraus, ${ }^{2}$ and Mohamad Cherry ${ }^{1}$ \\ ${ }^{1}$ Hematology-Oncology Section, Department of Medicine, Stephenson Cancer Center, The University of \\ Oklahoma Health Sciences Center, 800 NE 10th Street, Oklahoma City, OK 73104, USA \\ ${ }^{2}$ Department of Pathology, The University of Oklahoma Health Sciences Center, 940 Stanton L. Young Boulevard, \\ BMSB 451, Oklahoma City, OK 73104, USA \\ Correspondence should be addressed to Mohamad Khawandanah; mohamad-khawandanah@ouhsc.edu
}

Received 10 February 2014; Revised 21 April 2014; Accepted 23 April 2014; Published 13 May 2014

Academic Editor: Marie-Christine Kyrtsonis

Copyright (C) 2014 Mohamad Khawandanah et al. This is an open access article distributed under the Creative Commons Attribution License, which permits unrestricted use, distribution, and reproduction in any medium, provided the original work is properly cited.

\begin{abstract}
Cutaneous Hodgkin lymphoma is a rare condition. Specific neoplastic involvement can be primary (confined to the skin) or secondary to systemic involvement (metastatic). Cutaneous involvement by HL usually occurs late in the course and is associated with poor prognosis; however in some cases it can exhibit indolent behavior. Skin involvement with nonspecific cutaneous findings may represent a paraneoplastic syndrome. We describe a case of 46-year-old white male patient presented with rash and lymphadenopathy which led to the diagnosis of stage IVE mixed cellularity classical Hodgkin lymphoma with skin involvement. His disease was refractory to multiple lines of chemotherapy including (1) AVD (doxorubicin/bleomycin/dacarbazine), (2) brentuximab, and (3) bendamustine, he later achieved complete remission with (4) GCD (gemcitabine/carboplatin/dexamethasone) salvage regimen. Bleomycin was not given secondary to poor pulmonary function tests. His treatment was complicated after AVD with multiple pneumothoraces which unmasked the diagnosis of ZZ phenotype alpha-1 antitrypsin (ATT) deficiency. Simultaneous existence of Hodgkin lymphoma and ATT is rarely reported.
\end{abstract}

\section{Introduction}

Hodgkin lymphoma (HL) is a highly curable malignancy and represents around $10 \%$ of all lymphomas and approximately $0.6 \%$ of all cancers diagnosed annually [1]. It originates from germinal center or postgerminal center B cells, and a unique hallmark is in presence of Reed-Sternberg cells. Hodgkin lymphoma is classified as either classical or nodular lymphocyte predominant. According to the 2008 WHO classification, classical HL is subdivided into nodular sclerosis (70\%), mixed cellularity (20 to $25 \%$ ), lymphocyte rich (5\%), and lymphocyte depleted (less than 1\%) [2]. Management is broadly similar in all subtypes.

Hodgkin lymphoma typically presents as painless lymphadenopathy, which is frequently cervical, supraclavicular, and/or mediastinal. Cutaneous Hodgkin lymphoma is a rare condition that usually occurs late in the course of disease. Presentation with skin involvement has been reported in few cases [3]; however in primary cutaneous disease or skin only disease the incidence is exceedingly rare [4]. The incidence is variable from 0.5 to $3 \%[5,6]$.

On the other hand, alpha-1 antitrypsin (AAT) deficiency is relatively common but underrecognized with less than $10 \%$ of the estimated 100,000 Americans with AAT who were diagnosed [7]. Neutrophil elastase (NE) and ATT are a pair of protease and protease inhibitor counterparts that play a role in ATT deficiency pathogenesis [8]; ATT is serine protease inhibitor and A1 (SERPINA1) is an important serine protease inhibitor in humans. One of the main physiological roles of AAT is to inhibit NE released from triggered neutrophils, with an additional lesser role in defense against damage inflicted by other serine proteases, such as cathepsin $G$ and 


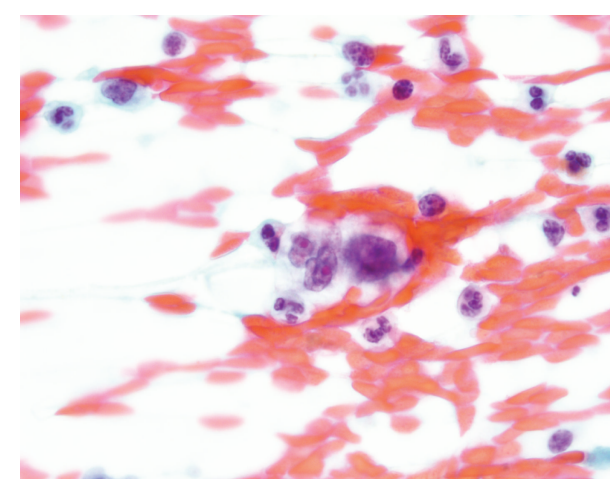

(a)

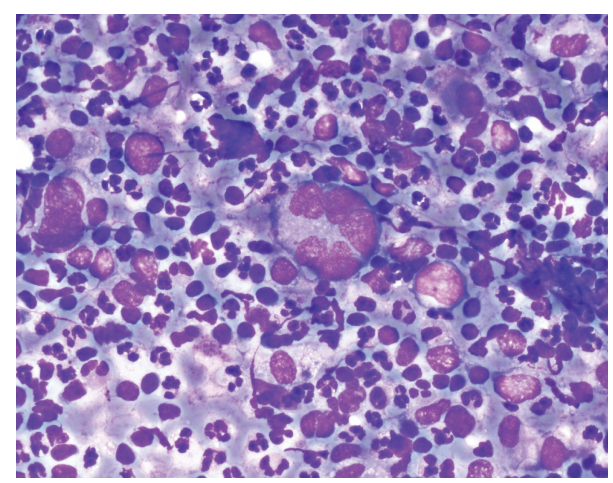

(b)

Figure 1: Pathology microscopy of FNA of the chest wall lesion on presentation: (a) 100x magnification, Papanicolaou stain: Reed-Sternberg cell in a mixed inflammatory background, and (b) 60x magnification, Diff Quik (modified Giemsa) stain: Reed-Sternberg cell in a mixed inflammatory background consisting of neutrophils, histiocytes, and small lymphocytes.

proteinase 3. Imbalance between $\mathrm{NE}$ and AAT can lead to tissue damage and subsequently may lead to carcinogenesis and tumor progression.

Deficiency of ATT has been described in association with increased risk of liver cancer, bladder cancer, gall bladder cancer, malignant lymphoma, and lung cancer. Elevated levels of NE may promote the development, invasion, and metastasis of many cancers [17]. Association of Hodgkin lymphoma and alpha-1 antitrypsin deficiency is rare, and the incidence of ATT deficiency in HL patients is around 5\% [14].

\section{Methods}

We searched Medline and PubMed for articles published under the term "cutaneous Hodgkin lymphoma" and the related terms "skin involvement," "alphal anti trypsin deficiency," "alpha-1 antitrypsin deficiency phenotypes," and "relapsed Hodgkin lymphoma" or "refractory Hodgkin lymphoma." We did not restrict references by language of publication, and references from relevant articles were also searched.

\section{Case Presentation}

A 46-year-old white male patient presented to our facility in July 2011 with complaints of painless lumps in his right side of the neck, right axilla, and left groin that appeared 3 months prior to presentation. He also noted a light red rash involving the right side of the neck extending to the right upper chest appeared simultaneously. He complained of effortless weight loss and fatigue. He denied any febrile illness or night sweats. He had a history of obstructive lung disease and GERD and underwent appendectomy as a child. He had a long standing history of smoking. There was no significant family history or known drug allergies. His physical exam was remarkable for cervical, right axillary, and left inguinal lymphadenopathy, in addition to a homogenous erythematous rash involving the upper chest and left neck. His initial laboratory work-up showed a hemoglobin of $12.3 \mathrm{~g} / \mathrm{dL}, \mathrm{WBC} 33,800 / \mathrm{mm}^{3}$, with a differential of $88 \%$ segmented neutrophils, $1 \%$ band, $5 \%$ lymphocytes, $4 \%$ monocytes, and $2 \%$ eosinophils, and a platelet count of $456,000 / \mathrm{mm} 3$. LDH was mildly elevated at $212 \mathrm{U} / \mathrm{L}$. Liver and kidney chemistry profiles were unremarkable. HIV and hepatitis serology tests were negative. A PET/CT scan showed extensive hypermetabolic anterior chest wall uptake with peak SUV 15.1, in addition to uptake in bilateral cervical, mediastinal, paraesophageal, precarinal, right internal mammary, left subpectoral, and right posterior paraspinal lymph nodes (LN). There was no FDG-avid uptake below the diaphragm. A large upper lung lobe bulla and smaller bullae and blebs in the left lower lobe were noted incidentally. The patient was admitted to the hospital to expedite work-up and obtain tissue diagnosis. He underwent fine needle aspiration (FNA) of the rash on the chest wall, which revealed large atypical cells consistent with Reed-Sternberg cells in a mixed inflammatory background, suspicious of HL (see Figure 1). FNA of right axillary also showed findings suspicious of $\mathrm{HL}$ (not shown).

Subsequently patient underwent open excisional biopsy of right cervical and left inguinal LN. His inguinal LN was benign with reactive changes, while the cervical biopsy was diagnostic for classical HL, mixed cellularity (see Figure 2). A bone marrow exam was normal. His final staging was IIE or considering the disease multifocal with his skin disease his stage would be IVE.

At this point our decision was to treat the patient with standard ABVD (doxorubicin, bleomycin, vinblastine, and dacarbazine), which is the standard of care, but unfortunately his pulmonary function test results were poor. His DLCO was $35 \%$, while his FEV1/FVC was $32 \%$ of predicted value. We decided to start treatment with AVD without bleomycin (Table 1). Cycle 1 was complicated with dental abscess and interruption of treatment. After completion of 6 cycles he achieved partial response. The patient started to complain of chest pain, dyspnea, and anxiety and presented to our ER with tachycardia and hypoxia. A CT scan was obtained to rule out pulmonary embolism which again demonstrated bullae and severe emphysematous changes. He subsequently developed spontaneous pneumothoraces involving both sides of the lungs and required 4 chest tubes. His hospital course was protracted and required multiple talc pleurodesis procedures. 
TABLE 1: List of chemotherapy agents utilized in our case.

\begin{tabular}{llll}
\hline Regimen & Description & Number of cycles given & Reference \\
\hline \multirow{2}{*}{ AVD without bleomycin } & Doxorubicin $25 \mathrm{mg} / \mathrm{m}^{2}$ IV on days 1 and 15 & 8 & {$[9]$} \\
& Vinblastine $6 \mathrm{mg} / \mathrm{m}^{2}$ IV on days 1 and 15 & & \\
\hline Brentuximab vedotin & Dacarbazine $375 \mathrm{mg} / \mathrm{m}^{2}$ IV on days 1 and 15 & 2 & {$[10]$} \\
\hline Bendamustine & Bentuximab $1.8 \mathrm{mg} / \mathrm{kg} \mathrm{IV}$ on day 1 & 5 & {$[11]$} \\
\hline \multirow{2}{*}{ GCD } & Gendamustine $120 \mathrm{mg} / \mathrm{m}^{2} /$ day IV on days 1 and 2 & 5 \\
& Carboplatin AUC $5 \mathrm{IV}$ on day 1 & {$[12]$} \\
\hline
\end{tabular}

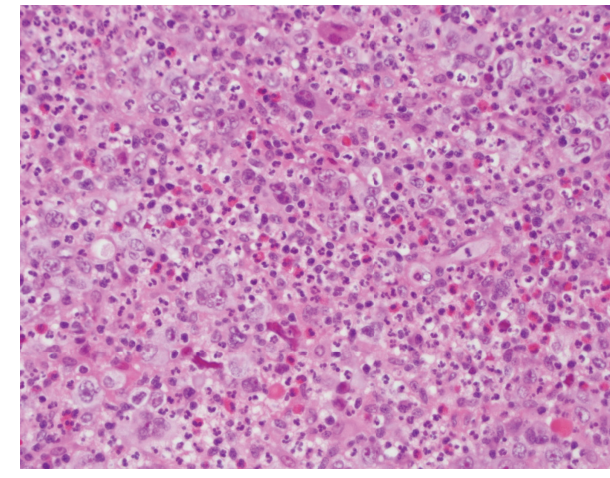

(a)

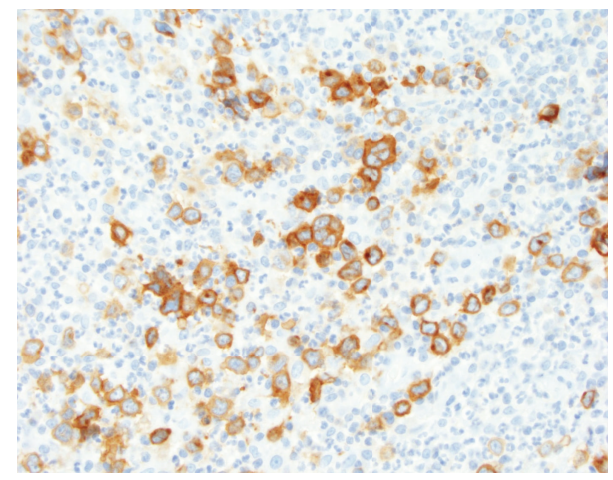

(b)

FIGURE 2: Pathology microscopy of excisional biopsy of a right cervical lymph node (a) showed effacement of the lymph node architecture by a mixed infiltrate of neutrophils, eosinophils, histiocytes, and small lymphocytes, with scattered Reed-Sternberg cells (H\&E stain 40x). (b) Immunohistochemical staining for CD30 highlighted the Reed-Sternberg cells (40x).

This raised suspicion of alpha-1 antitrypsin deficiency as the cause of his pulmonary complications and led to more work-up. His AAT level was $30 \mathrm{mg} / \mathrm{dL}$; repeat testing for verification showed level of $17 \mathrm{mg} / \mathrm{dL}$ (normal range is 90$200 \mathrm{mg} / \mathrm{dL}$ ). The AAT phenotype was homozygous ZZ. Two months later, the patient was discharged from the hospital with a left side Heimlich flutter valve and home oxygen. He was requiring only $2 \mathrm{~L} / \mathrm{min}$ of oxygen by nasal cannula. We treated him with an additional 2 cycles of AVD and his disease progressed. He developed left cervical flesh-like lesion on top of his lymphadenopathy. Biopsy was not feasible and patient declined bone marrow biopsy for restaging. Due to his multiple medical problems and poor performance status, we decided to treat him with IV brentuximab vedotin every 3 weeks as we believed he could not tolerate intensive salvage cytotoxic chemotherapy. He tolerated this biologic agent with no complications and his original rash improved significantly. Interim follow-up PET scan showed positive, but incomplete, response (see Figure 3). After 8 cycles, he developed bulky progression on PET scan evaluation, mainly in the right supraclavicular area, with SUV of 12, in addition to having stable disease in the right axilla. The patient was not considered for stem cell transplant secondary to his severe pulmonary disease.

Restaging FNA of his supraclavicular lesion confirmed the same diagnosis of $\mathrm{HL}$, but his axillary lesion was negative for malignancy. The repeated bone marrow exam remained normal. A third line chemotherapy regimen consisting of IV bendamustine every 3 weeks started thereafter. He tolerated this regimen but progressed after 2 cycles. His rash recurred again on the same area on the chest covering the supraclavicular LN with ulcerated nodule and flesh color. At that point we referred the patient for radiation therapy, but this was not feasible as he could not lay flat secondary to severe orthopnea.

The patient requested to be treated; however options were limited for clinical trial enrollment in his case, so we treated him with fourth line salvage chemotherapy regimen consisting of gemcitabine/carboplatin/dexamethasone (GCD) with growth factor support. Therapy was complicated with interruptions and dose reductions secondary to hematologic toxicities. Postcycle 2 PET scan showed near complete remission without clinically palpable lymph nodes. He remained oxygen dependent and his rash resolved completely. The patient noticed increased dyspnea after cycle 3 within days after chemotherapy, and he requested discontinuation of therapy after cycle 5. Posttreatment PET scan was compatible with complete metabolic remission (see Figure 4).

Currently, the patient is being treated with intravenous augmentation via the infusion of pooled human alpha1 antiprotease. He is doing well 8 months after stopping chemotherapy, with no evidence of lymphoma recurrence. 


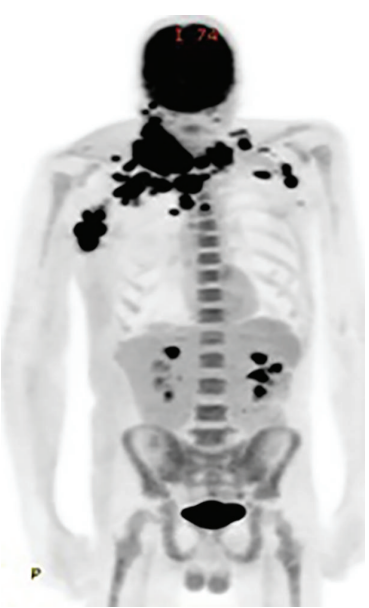

(a)

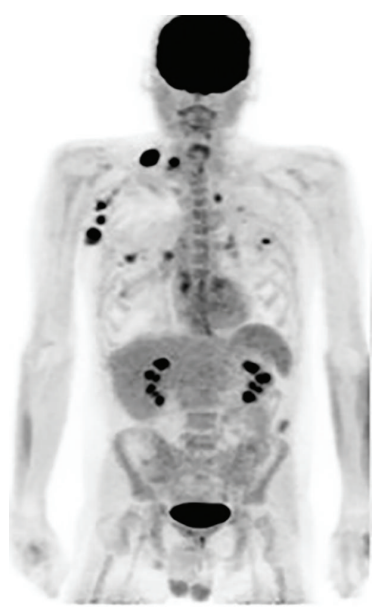

(b)

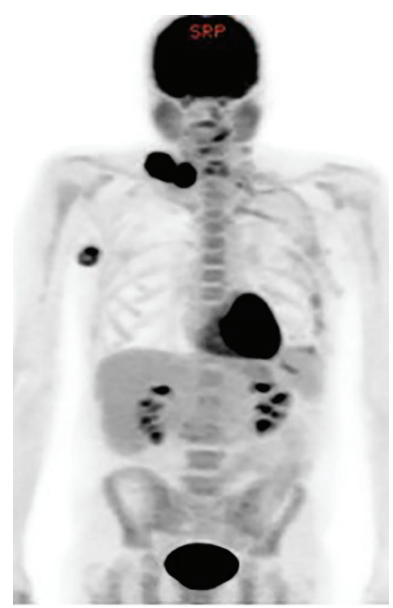

(c)

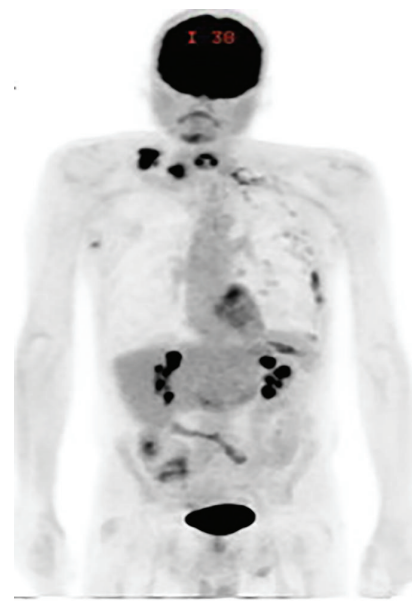

(d)

Figure 3: (a) PET scan at presentation, (b) PET scan done after 6 cycles of AVD, (c) PET scan after 8 cycles of AVD, and (d) PET scan after 2 cycles of brentuximab.

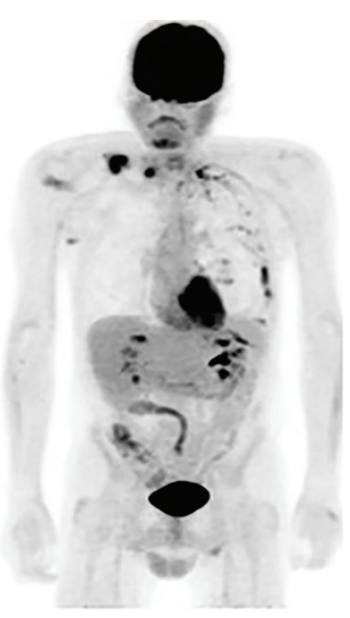

(a)

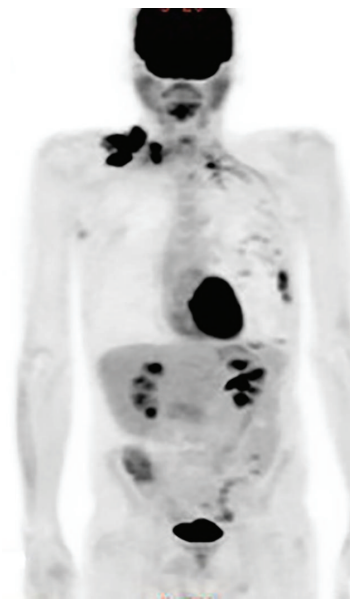

(b)

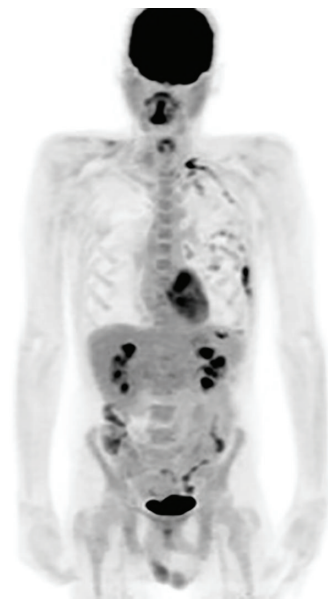

(c)

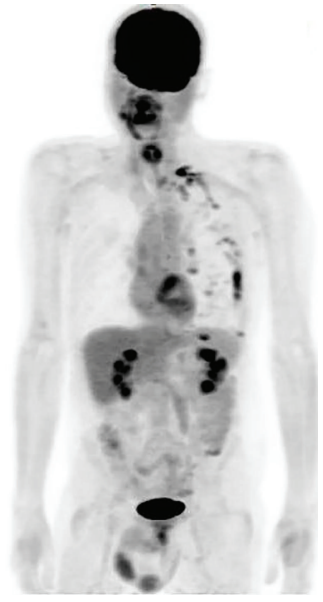

(d)

FIGURE 4: (a) PET scan during brentuximab therapy, (b) PET scan after 2 cycles of bendamustine, (c) PET scan after 2 cycles of GCD, and (d) PET scan at conclusion of treatment with GCD. Pleurodesis inflammatory changes remained on imaging.

\section{Discussion}

Our case is unique, as rash is a very uncommon initial presentation of Hodgkin lymphoma. Furthermore, the association between lymphoma and alpha-1 antitrypsin deficiency is scarcely described in the literature.

Cutaneous Hodgkin lymphoma was first described by the German physician Grosz in 1906 [18]. This rare condition is thought to have decreasing incidence in recent decades, owing to the improved treatment modalities of patients with Hodgkin lymphoma. In addition to rarity, skin involvement carries an ominous prognosis but can be indolent if systemic disease was controlled properly [19]. Cerroni et al. found that histology of cutaneous specific manifestations of Hodgkin lymphoma correlates with that of the nodal counterpart in most cases [20].
TABLE 2: Types of ulcerative lesions in cutaneous Hodgkin lymphoma.

\begin{tabular}{ll}
\hline Types of ulcerative lesions & Description \\
\hline Grosz-Hirschfield & Ulceration develops on nodule \\
& $\begin{array}{l}\text { Ulceration develops in skin directly } \\
\text { infiltrated from underlying lymph } \\
\text { node or other tissues }\end{array}$ \\
Coleman-Anderson & $\begin{array}{l}\text { Occurs when a primary cutaneous } \\
\text { Hodgkin lymphoma ulcerates }\end{array}$ \\
\hline
\end{tabular}

Cutaneous involvement can range from simple erythematous rash to spectrum of papular, nodular, nodular-ulcerative, plaque-like, and infiltrative lesions $[6,21,22]$ (see Table 2 
TABLE 3: Correlation between ATT phenotype and emphysema, lymphoma, and lung cancer.

\begin{tabular}{|c|c|c|c|}
\hline Phenotype & Risk of emphysema [13] & Incidence of lymphoma [14] & Risk of lung cancer $[15,16]$ \\
\hline MM (normal) & No increase & Baseline risk & Baseline risk \\
\hline $\mathrm{MZ}$ & Possible mild increase & $5.8 \%$ & \\
\hline SS & No increase & $0.4 \%$ & \\
\hline SZ & 20 to $50 \%$ & $\mathrm{n} / \mathrm{a}$ & Hypothetical increased risk \\
\hline $\mathrm{ZZ}$ & 80 to $100 \%$ & $\mathrm{n} / \mathrm{a}$ & \\
\hline Null & $100 \%$ by age 30 & $\mathrm{n} / \mathrm{a}$ & \\
\hline
\end{tabular}

for ulcerative lesion types). Other nonspecific skin manifestations in patients with Hodgkin lymphoma include Addisonian pigmentation, pruritus, prurigo eruption, acquired ichthyosis, erythroderma, alopecia, and recurrent herpes zoster infection [23].

Callea et al. studied ATT phenotypes of 228 patients diagnosed with lymphoma and 250 healthy controls and concluded that there was an increased incidence of abnormal phenotypes in lymphoma patients, with no prevalence for a special lymphoma type (Table 3 ). In the same report, 7 patients were described with Hodgkin lymphoma and MZ phenotype in addition to 1 patient with unknown status [14].

Although there is a reported association between AAT polymorphism and different types of cancer, this association with hematological malignancies is unknown [24]. Topic et al. described a study of identification of ATT phenotypes in 151 patients with hematologic malignancies and 272 healthy controls. There was no difference in the frequency of deficient AAT alleles ( $\mathrm{Pi} \mathrm{Z}$ and $\mathrm{Pi}$ S) between patients and controls, but there was higher frequency of PiM1M1 homozygote and PiM1 allele in patients with hematologic malignancies, suggesting that even AAT polymorphisms with functionally normal phenotypes may be associated with an increased risk of hematologic disease.

\section{Conclusions}

We present a unique case of skin involvement with Hodgkin lymphoma that followed the systemic pattern of the disease in terms of response to chemotherapy. Treatment of our patient's refractory lymphoma was challenging due to his poor performance status and pulmonary complications. Despite the diagnosis of alpha-1 antitrypsin deficiency, he tolerated multiple lines of chemotherapy. Simultaneous existence of both disorders is rarely reported.

Regardless of primary or secondary lymphoma origin of skin lesions, treatment should be directed systematically with conventional chemotherapy. Judicious chemotherapy selection is important in such refractory cases.

\section{Conflict of Interests}

All the authors have no conflict of interests.

\section{Authors' Contribution}

All authors participated in writing this paper and agreed on the final version.

\section{References}

[1] A. Jemal, R. Siegel, E. Ward, Y. Hao, J. Xu, and M. J. Thun, "Cancer statistics, 2009," CA: Cancer Journal for Clinicians, vol. 59, no. 4, pp. 225-249, 2009.

[2] E. Campo, S. H. Swerdlow, N. L. Harris et al., "Hodgkin lymphoma," in WHO, Classification of Tumours of Haematopoietic and Lymphoid Tissues, International Agency for Research on Cancer, Lyon, France, 4th edition, 2008.

[3] A. Fernandez-Flores, "The early reports on cutaneous involvement by hodgkin lymphoma," American Journal of Dermatopathology, vol. 31, no. 8, pp. 853-854, 2009.

[4] S. Kumar, D. W. Kingma, W. B. Weiss et al., "Primary cutaneous Hodgkin's disease with evolution to systemic disease. Association with the Epstein-Barr virus," The American Journal of Surgical Pathology, vol. 20, pp. 754-759, 1996.

[5] C. E. Introcaso, J. Kantor, D. L. Porter, and J. M. JunkinsHopkins, "Cutaneous Hodgkin's disease," Journal of the American Academy of Dermatology, vol. 58, no. 2, pp. 295-298, 2008.

[6] R. M. White and J. W. Patterson, "Cutaneous involvement in Hodgkin's disease,” Cancer, vol. 55, no. 5, pp. 1136-1145, 1985.

[7] J. K. Stoller and M. Brantly, "The challenge of detecting alpha-1 antitrypsin deficiency," Chronic Obstructive Pulmonary Disease, vol. 10, supplement 1, pp. 26-34, 2013.

[8] R. A. Sandhaus and G. Turino, "Neutrophil elastase-mediated lung disease," Chronic Obstructive Pulmonary Disease, vol. 10, supplement 1, pp. 60-63, 2013.

[9] G. Bonadonna, R. Zucali, and S. Monfardini, "Combination chemotherapy of Hodgkin's disease with adriamycin, bleomycin, vinblastine, and imidazole carboxamide versus MOPP," Cancer, vol. 36, no. 1, pp. 252-259, 1975.

[10] A. Younes, A. K. Gopal, S. E. Smith et al., "Results of a pivotal phase II study of brentuximab vedotin for patients with relapsed or refractory Hodgkin's lymphoma," Journal of Clinical Oncology, vol. 30, pp. 2183-2189, 2012.

[11] A. J. Moskowitz, P. A. Hamlin Jr., M. A. Perales et al., "Phase II study of bendamustine in relapsed and refractory Hodgkin lymphoma," Journal of Clinical Oncology, vol. 31, pp. 456-460, 2013.

[12] A. K. Gopal, O. W. Press, A. R. Shustov et al., "Efficacy and safety of gemcitabine, carboplatin, dexamethasone, and rituximab in patients with relapsed/refractory lymphoma: a prospective multi-center phase II study by the Puget Sound Oncology Consortium," Leukemia and Lymphoma, vol. 51, no. 8, pp. 15231529, 2010.

[13] American Thoracic Society and European Respiratory Society, "American Thoracic Society/European Respiratory Society statement: standards for the diagnosis and management of individuals with alpha-1 antitrypsin deficiency," The American 
Journal of Respiratory and Critical Care Medicine, vol. 168, pp. 818-900, 2003.

[14] F. Callea, G. Massi, and C. De Wolf-Peeters, "Alpha-1antitrypsin phenotypes in malignant lymphoma," Journal of Clinical Pathology, vol. 35, no. 11, pp. 1213-1215, 1982.

[15] P. Yang, Z. Sun, M. J. Krowka et al., "Alphal-antitrypsin deficiency carriers, tobacco smoke, chronic obstructive pulmonary disease, and lung cancer risk," Archives of Internal Medicine, vol. 168, no. 10, pp. 1097-1103, 2008.

[16] P. Yang, W. R. Bamlet, Z. Sun et al., "Alphal-antitrypsin and neutrophil elastase imbalance and lung cancer risk," Chest, vol. 128, pp. 445-452, 2005.

[17] Z. Sun and P. Yang, "Role of imbalance between neutrophil elastase and $\alpha 1$-antitrypsin in cancer development and progression," Lancet Oncology, vol. 5, no. 3, pp. 182-190, 2004.

[18] S. Bluefarb, Cutaneous Manifestations of the Malignant Lymphomas, vol. 219, Charles C Thomas, Springfield, Ill, USA, 1959.

[19] J. Rubins, “Cutaneous Hodgkin's disease. Indolent course and control with chemotherapy," Cancer, vol. 42, no. 3, pp. 1219-1221, 1978.

[20] L. Cerroni, C. Beham-Schmid, and H. Kerl, "Cutaneous Hodgkin's disease: an immunohistochemical analysis," Journal of Cutaneous Pathology, vol. 22, no. 3, pp. 229-235, 1995.

[21] J. L. Smith Jr. and J. J. Butler, "Skin involvement in Hodgkin's disease," Cancer, vol. 45, no. 2, pp. 354-361, 1980.

[22] L. C. Goldberg, “Cutaneous Hodgkin's disease," Cutis, vol. 17, no. 1, pp. 115-118, 1976.

[23] R. M. MacKie, "Cutaneous lymphomas and lymphocytic infiltrates," in Textbook of Dermatology, R. H. Champion, D. A. Burns, and S. M. Breathnach, Eds., vol. 3, pp. 2373-2402, Blackwell Science, Oxford, UK, 6th edition, 1998.

[24] A. Topic, Z. Juranic, S. Jelic, and I. G. Magazinovic, "Polymorphism of alpha-1-antitrypsin in hematological malignancies," Genetics and Molecular Biology, vol. 32, no. 4, pp. 716-719, 2009. 


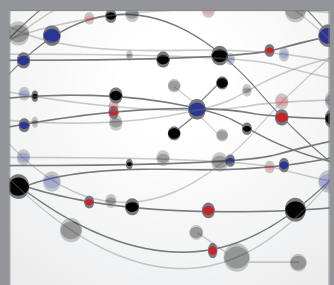

The Scientific World Journal
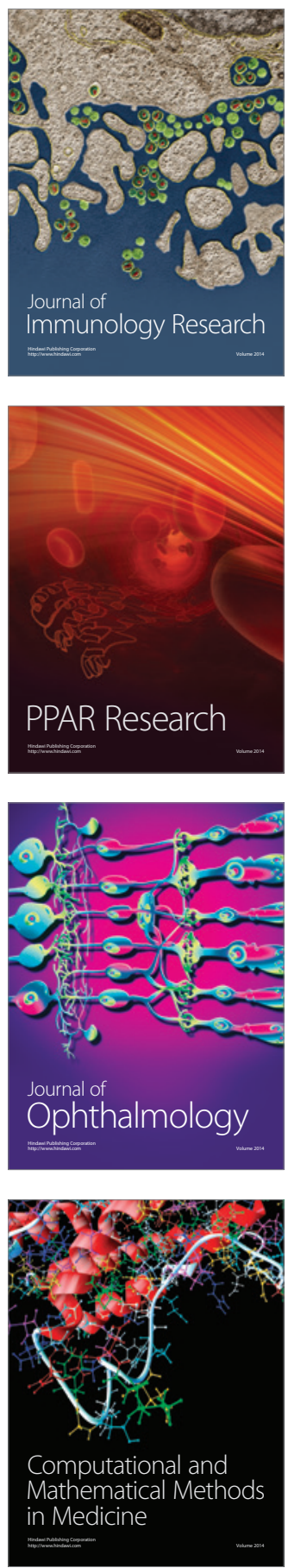

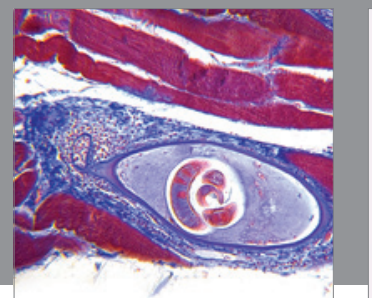

Gastroenterology

Research and Practice
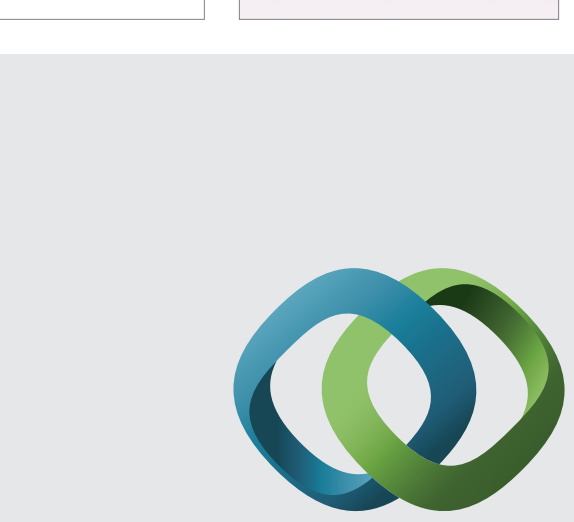

\section{Hindawi}

Submit your manuscripts at

http://www.hindawi.com
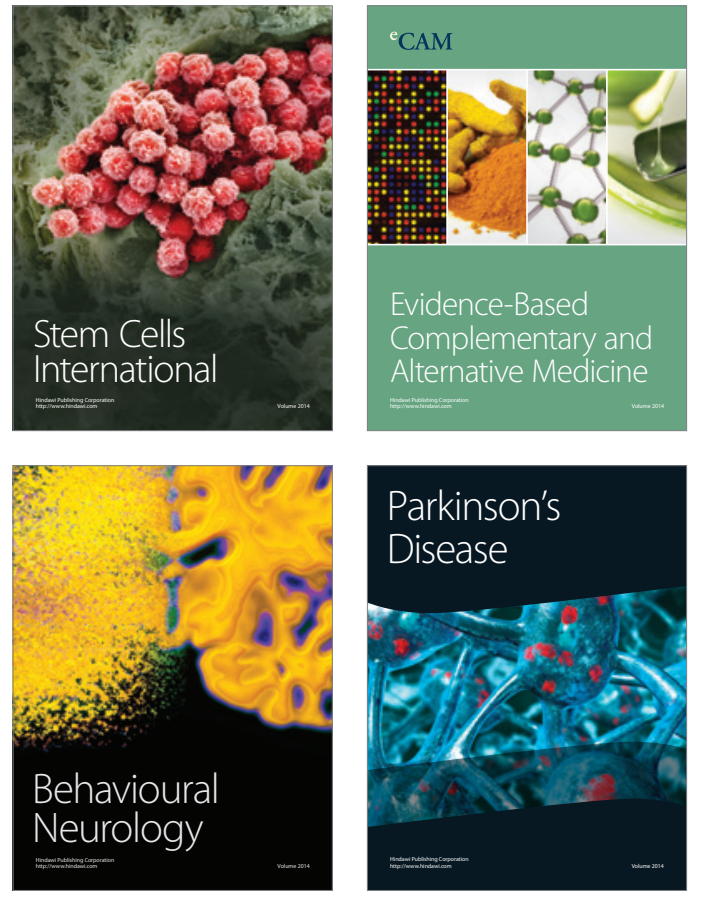
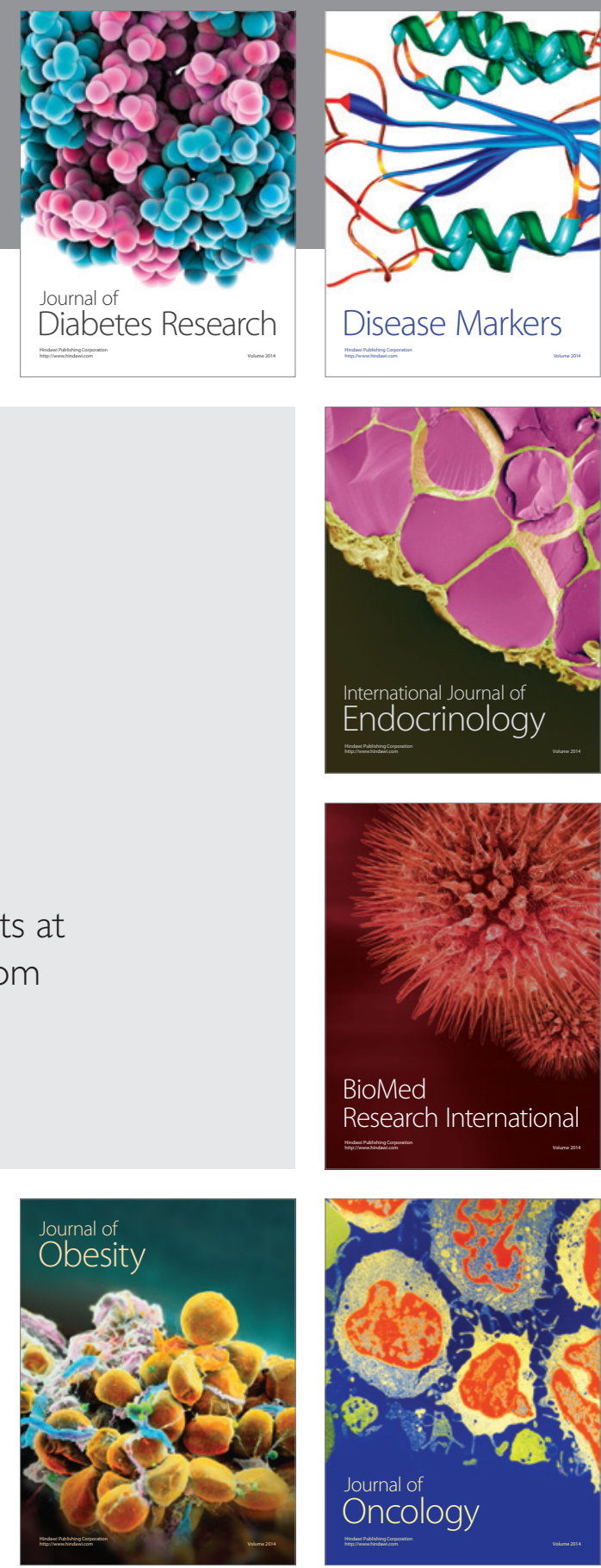

Disease Markers
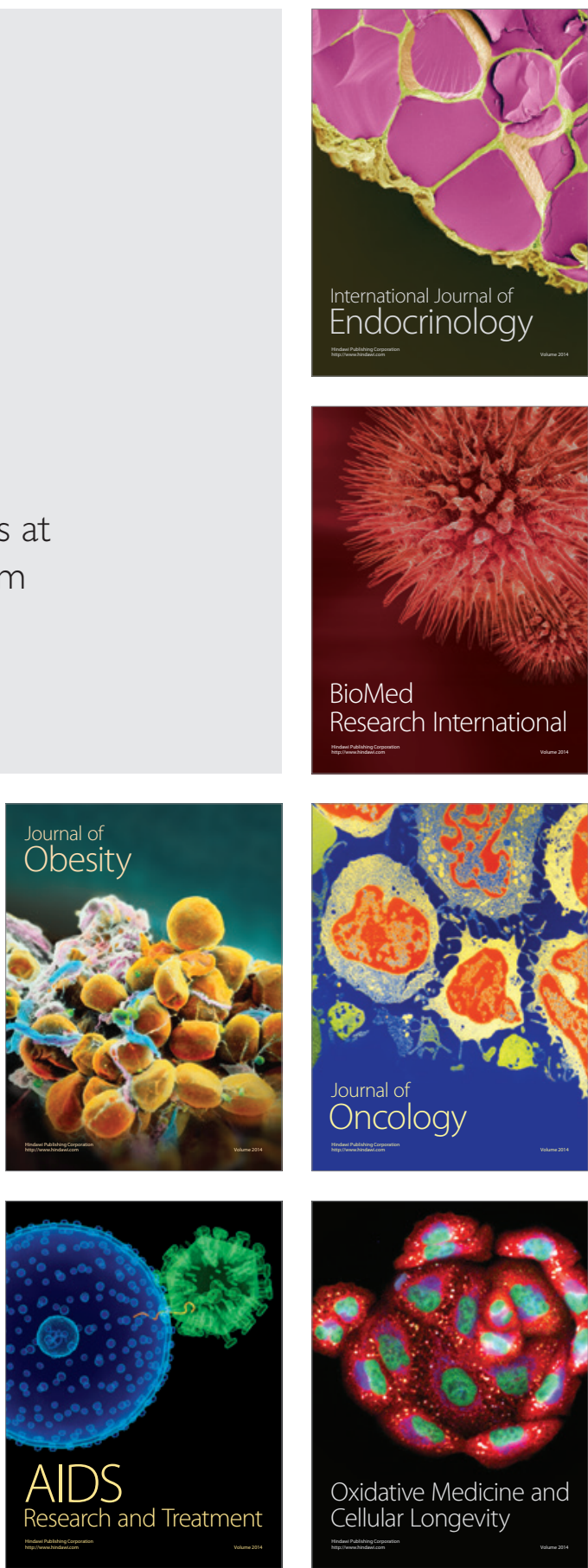